\title{
Bone aluminium in haemodialysed patients and in rats injected with aluminium chloride: relationship to impaired bone mineralisation
}

\author{
H. A. Ellis 1 , J. H. MCCARTHY ${ }^{2}$, AND J. HERRINGTON²
}

From the ${ }^{1}$ Department of Pathology, University of Newcastle upon Tyne and the ${ }^{2}$ Atomic Weapons Research Establishment, Aldermaston, Berkshire, UK

SUMMARY Iliac bone aluminium was determined by neutron activation analysis in 34 patients with chronic renal failure and in eight control subjects. In 17 patients treated by haemodialysis there was a significant increase in the amount of aluminium (mean $\pm \mathrm{SE}=152 \pm 30 \mathrm{ppm}$ bone ash). In eight patients treated by haemodialysis and subsequent renal transplantation, bone aluminium was still significantly increased ( $92 \pm 4 \cdot 5 \mathrm{ppm}$ bone ash) but was less than in the haemodialysed patients. In some patients aluminium persisted in bone for many years after successful renal transplantation. There was no relationship between hyperparathyroidism and bone aluminium. Although no statistically significant relationship was found between the mineralisation status of bone and bone aluminium, patients dialysed for the longest periods tended to be those with the highest levels of aluminium, osteomalacia, and dialysis encephalopathy.

In 20 rats given daily intraperitoneal injections of aluminium chloride for periods of up to three months, there was accumulation of aluminium in bone (163 $\pm 9 \mathrm{ppm}$ ash) to levels comparable to those obtained in the dialysis patients, and after about eight weeks osteomalacia developed. The increased bone aluminium and osteomalacia persisted after injections had been stopped for up to 49 days, although endochondral ossification was restored to normal. As a working hypothesis it is suggested that aluminium retained in the bone of the dialysis patients and the experimental animals interferes with normal mineralisation.

Patients with chronic renal failure treated by longterm intermittent haemodialysis may develop a modified form of renal osteodystrophy (Ellis and Peart, 1971a), characterised by osteomalacia in the presence of minimal or no osteitis fibrosa (Ellis et al., 1977). This form of dialysis osteomalacia does not improve after treatment with 1,25 dihydroxy vitamin $D_{3}\left(1,25(\mathrm{OH})_{2} \mathrm{D}_{3}\right)$ or with $1 \alpha$ hydroxy vitamin $\mathrm{D}_{3}\left(1_{a} \mathrm{OHD}_{3}\right)$ (Pierides et al., 1976; Ellis et al., 1977), and deficiency of $1,25(\mathrm{OH})_{2} \mathrm{D}_{3}$ is not its sole cause. Recently there has been speculation concerning the role of aluminium intoxication in the production of dialysis osteomalacia and dialysis dementia (Alfrey et al., 1976; Platts et al., 1977; Elliott et al., 1978; McDermott et al., 1978; Ward et al., 1978). The main sources of aluminium are its salts in the dialysate water and aluminium hydroxide administered to control hyperphosphataemia. Hyperaluminaemia may result from the use

Received for publication 23 January 1979 of aluminium resins in renal failure (Berlyne et al.. 1970), and bone concentrations of aluminium may be high in patients treated by haemodialysis (Parsons et al., 1971). Evidence linking aluminium intoxication and dialysis osteomalacia is largely circumstantial, and there is no proven causal connection between the development of osteomalacia and the increased concentration of aluminium in the blood or bone.

Earlier experimental toxicity studies in animals have given conflicting results. Berlyne et al. (1972) described a syndrome of periorbital bleeding, lethargy, anorexia, and death in uraemic and non-uraemic rats after oral or parenteral administration of aluminium salts. This was accompanied by hyperaluminaemia and increased concentrations of aluminium in the tissues, including bone and brain. Histological studies of bone were not reported. Thurston et al. (1972), as a result of their studies on the effects of aluminium hydroxide in normal rats and rats with chronic renal failure, concluded that aluminium accumulated in bone, but that any 
mineralisation defect that occurred resulted from the accompanying hypophosphataemia and could be prevented by giving the animals a dietary supplement of phosphate. In their opinion, the symptoms of aluminum toxicity described by Berlyne et al. (1972) are non-specific.

We wished to reassess the possible toxicity of aluminium in animals with intact kidneys by administering aluminium parenterally to avoid hypophosphataemia and to see if histological osteomalacia developed when the bone aluminium was increased to a concentration similar to that found in the bones of our dialysis patients. Dialysis osteomalacia is a serious problem in Newcastle upon Tyne, and bone samples from some of our patients were among those with most aluminium in the previously reported data (Parsons et al., 1971). The measurements were then made on bone ash by thermal neutron activation analysis without allowance for the activa- tion of phosphorus to ${ }^{28} \mathrm{Al}$, though the omission did not significantly affect the results at the levels observed in the samples from Newcastle patients. In this paper we report (i) values for the aluminium content of bone from control subjects and from non-dialysed and dialysed patients with chronic renal failure, using an improved neutron activation analysis technique (Goode et al., 1977), and (ii) the effects of the long-term intraperitoneal administration to rats of aluminium chloride, with particular reference to bone mineralisation and increased bone aluminium.

\section{Materials and methods}

\section{PATIENTS AND METHODS}

Iliac bone was obtained at necropsy (32) or at biposy (2) from 34 patients with chronic renal failure. Details of these patients are given in Table 1.

Table 1 Details of patients with chronic renal failure and summary of bone histology and aluminium data

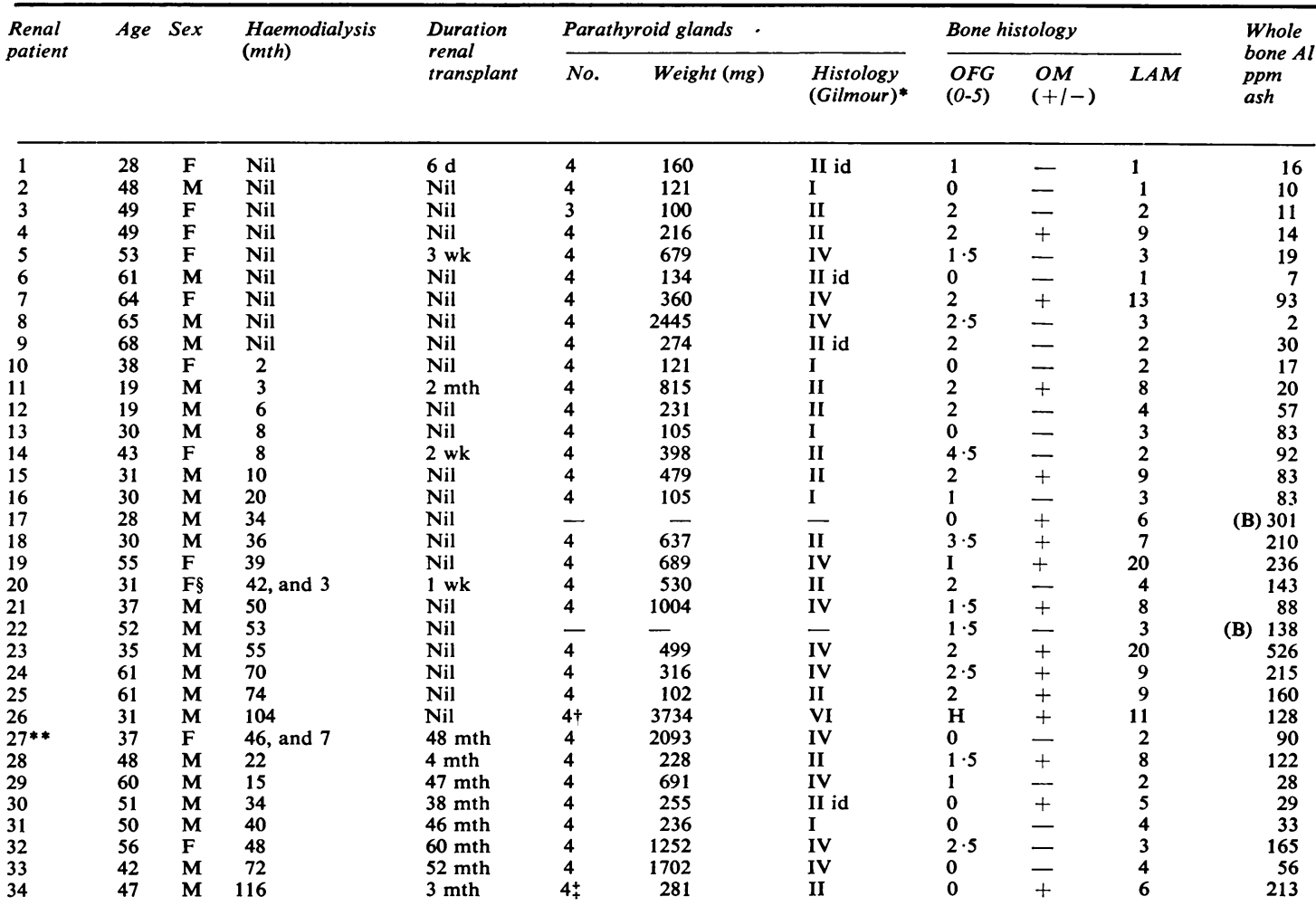

*See Gilmour (1947); ** Case 27 dialysed $46 \mathrm{mth}$ then renal transplant for $48 \mathrm{mth}$ but returned to dialysis $7 \mathrm{mth}$ before death.

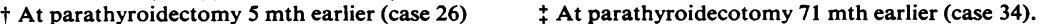

$\S$ Transplant unsuccessful, returned to PD/HD for $3 \mathrm{mth}$ before death (case 20).

(B), iliac bone biopsy; $\mathbf{H}$ still evidence of osteitis fibrosa but healing compared with previous biopsies; OFG, osteitis fibrosa grade on scale 0-5; OM, osteomalacia; LAM, maximum number of birefringent lamellas in osteoid seams. 
Eight control samples of iliac bone were examined from individuals who had died suddenly from road accidents, etc. Each necropsy sample comprised a block of compact and cancellous bone measuring about $5 \mathrm{~mm}$ wide and $50 \mathrm{~mm}$ long, including the crest. The two transiliac biopsy samples were obtained with a $7 \mathrm{~mm}$ diameter trephine. Samples of whole bone were ashed at $500{ }^{\circ} \mathrm{C}$ and analysed for aluminium, as previously described by Goode et al. (1977). The results are expressed as elemental aluminium, parts per million of bone ash ( $\mathrm{Al} \mathrm{ppm).}$ In 12 of the renal patients and in three controls, a second specimen of iliac bone was separated into cancellous and compact components, which were then analysed separately. Undecalcified and decalcified sections of iliac bone were examined histologically to assess the nature and severity of any bone disease (Ellis and Peart, 1973). Undecalcified bone was embedded in Polymaster 1209AC resin (Bondaglass Voss Ltd), $5 \mu$ thin sections were cut with a Jung $\mathrm{K}$ Microtome. The parathyroid glands were removed, weighed, and examined histologically in the renal patients at necropsy.

\section{ALUMINIUM CHLORIDE}

An aqueous solution was made of anhydrous aluminium chloride (BDH) to give a concentration of $2.7 \mathrm{~g}$ elemental aluminium per litre. From $0.1 \mathrm{ml}$ $(0.27 \mathrm{mg}$ aluminium) to $1.0 \mathrm{ml}$ of this was injected intraperitoneally daily, as detailed below.

\section{R A T S}

Twenty-six outbred Wistar rats were used in two experiments:

(1) Six rats weighing 145-170 g (mean $156 \pm 9 \mathrm{~g}$ ) were used. After a test dose of $2.7 \mathrm{mg}$ aluminium intraperitoneally, which resulted in acute peritonism, the animals were rested for seven days before restarting with one-tenth this dose. Four were then injected once daily intraperitoneally with $0.27 \mathrm{mg}$ aluminium, increasing gradually to $1.89 \mathrm{mg}$ aluminium, for five days in each week for an overall period of 52 days. Each animal received 33 to $38 \mathrm{mg}$ of aluminium. Two rats served as controls and v.ere injected intraperitoneally with saline.

(2) Twenty rats weighing $280-430 \mathrm{~g}$ (mean $347 \pm$ $38 \mathrm{~g}$ ) were used. Sixteen were injected with aluminium intraperitoneally as in the first experiment, starting with $0.27 \mathrm{mg}$ but increasing in some to $2.7 \mathrm{mg}$ aluminium per day. Overall periods for the injections varied from 48 to 85 days, and in five animals no further injections were given after courses lasting 63 or 84 days until sacrifice 27 or 49 days later. Each animal received 38 to $109 \mathrm{mg}$ of aluminium. Four controls were injected intraperitoneally with saline.
All rats were allowed free access to water and rat cake diet 86 (North Eastern Farmers Ltd, Bannermill, Aberdeen) and were weighed regularly. Blood was obtained by cardiac puncture at the end of each experiment for the estimation of serum calcium, phosphorus, and alkaline phosphatase. A whole femur from each rat was ashed, and its aluminium content was determined as for the human iliac bone. In 10 rats the diaphysis of the other femur was analysed separately after removal of the marrow. Radiographs of the tibiae and femora were obtained to allow direct radiological comparison of isolated control and test bones. The length of each tibia and the cortical widths at the mid diaphysis were determined from the projected radiographic image magnified $\times 3$ using a photographic enlarger. Decalcified and plastic-embedded, undecalcified sections of femora and/or tibiae were examined from each animal. Undecalcified sections were stained by Goldner's and von Kossa techniques, and the calcification front was stained with toluidine blue.

\section{Results}

HUMAN DATA

The data for the eight control subjects are given in Table 2. The mean whole bone aluminium is $5 \cdot 7 \pm 1 \cdot 0 \mathrm{ppm}$ bone ash.

Table 2 Aluminium in iliac bone from eight control subjects

\begin{tabular}{lllll}
\hline No. & Age/Sex & Cause of sudden death & $\begin{array}{l}\text { Bone aluminium } \\
\text { (ppm ash) }\end{array}$ \\
\hline 1 & 19 & M & Road accident & 6 \\
2 & 21 & M & Road accident & 9 \\
3 & 23 & M & Road accident & 2 \\
4 & 25 & F & Barbiturate poisoning & 5 \\
5 & 26 & F & Aspirin poisoning & 4 \\
6 & 57 & M & Drowning & 10 \\
7 & 68 & F & Coronary atheroma & 7 \\
8 & 75 & M & Road accident & 3 \\
\hline
\end{tabular}

The data for the 34 renal patients are summarised in Table 1.

Non-haemodialysed group (9 patients; cases 1-9, Table 1)

The mean bone aluminium is $22 \cdot 4 \pm 9 \cdot 2 \mathrm{ppm}$ bone ash, which is not significantly different from that for the control group $(P>0 \cdot 10)$. Some individual values are higher, however, and cases 7 and 9 exceed $20 \mathrm{ppm}$ Al. Case 7 had taken large amounts of oral aluminium hydroxide. If case 7 is omitted, then the mean bone aluminium for the non-dialysed renal patients is $13 \cdot 6 \pm 8 \cdot 5 \mathrm{ppm}$, which is significantly different from that of the controls $(0.05>\mathrm{P}>$ 0.02 ). 
Haemodialysed group (17 patients; cases 10-26, Table 1)

The mean bone aluminium is $151 \cdot 8 \pm 30 \mathrm{ppm}$ bone ash, which is significantly increased compared with the controls $(P<0.01)$ and the non-dialysed renal group $(\mathrm{P}<0.01)$.

Haemodialysed and renal transplant group (8 patients; cases 27-34, Table 1)

The mean bone aluminium is $92 \pm 4.5 \mathrm{ppm}$ ash, which is significantly different from that for the controls $(\mathrm{P}<0.01)$ and the non-dialysed renal patients $(P<0.02)$ but not the dialysed renal patients $(P>0 \cdot 10)$. Bone aluminium was still increased in the seven patients who had had a successful renal transplant for periods varying from four to 60 months.

In this group of patients the bone aluminium appeared to be less than expected, considering the duration of dialysis before transplantation. Thus, the matching of pairs of patients, with and without renal transplants, on a basis of the duration of dialysis shows that bone aluminium is less than expected in five of six patients treated by transplantation, but this is not statistically significant.

The results of the bone aluminium estimations for the control and various renal groups are summarised in Fig. 1 and Tables 3 and 4.

Aluminium in compact and cancellous bone

The amounts of aluminium in whole bone, cancellous bone, and cortical bone relating to three control subjects and 12 patients with renal disease are given in Table 5. Usually there is most aluminium

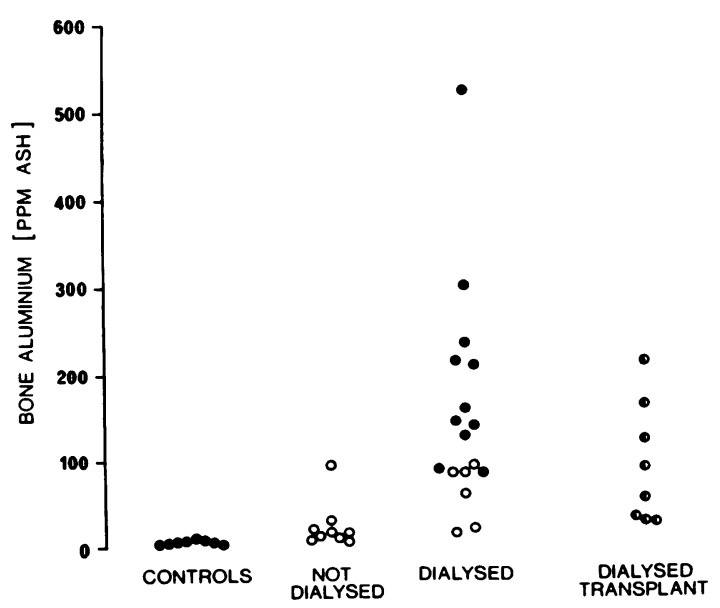

Fig. 1 Iliac bone aluminium in control subjects and in patients with chronic renal failure. Open circles in the dialysed group indicate patients dialysed $\leqslant 10$ months.
Table 3 Mean values for iliac bone aluminium in control subjects and patients with renal disease

\begin{tabular}{|c|c|c|c|}
\hline Group & $\begin{array}{l}\text { No. of } \\
\text { subjects }\end{array}$ & $\begin{array}{l}\text { Whole bone } \\
\text { (Range) }\end{array}$ & $\begin{array}{l}\text { Aluminium (ppm ash) } \\
(\text { mean } \pm S E)\end{array}$ \\
\hline $\begin{array}{l}\text { Control } \\
\text { Renal }\end{array}$ & 8 & $2-10$ & $5 \cdot 7 \pm 1 \cdot 0$ \\
\hline $\begin{array}{l}\text { Non-dialysed } \\
\text { Dialysed } \\
\text { Dialysed-transplant }\end{array}$ & $\begin{array}{r}9 \\
17 \\
8\end{array}$ & $\begin{array}{c}2-93 \\
17-526 \\
28-213\end{array}$ & $\begin{aligned} 22 \cdot 4 & \pm 9 \cdot 2 \\
151 \cdot 8 & \pm 30 \cdot 0 \\
92 \cdot 0 & \pm 24 \cdot 5\end{aligned}$ \\
\hline
\end{tabular}

Table 4 Iliac bone aluminium. Comparison of mean values between controls and groups of patients with renal disease

\begin{tabular}{ll}
\hline Comparison between & $P$ \\
\hline Controls/Renal & $>0.10$ \\
Controls/Dialysed & $<0.01$ \\
Controls/Dialysed-transplant & $<0.01$ \\
Renal/Dialysed & $<0.01$ \\
Renal/Dialysed-transplant & $<0.02$ \\
Dialysed/Dialysed-transplant & $>0.10$ \\
\hline
\end{tabular}

Table 5 Human iliac bone aluminium related to site in three 'control' and 12 'renal disease' subjects

\begin{tabular}{|c|c|c|c|c|}
\hline \multirow[t]{2}{*}{ Subject } & & \multicolumn{3}{|c|}{ Bone aluminium (ppm bone ash) } \\
\hline & & Cortical & Cancellous & Whole \\
\hline Control & 2 & 9 & - & 9 \\
\hline , & 3 & $<2$ & $<2$ & $<2$ \\
\hline , & 8 & $<2$ & $<2$ & 3 \\
\hline Renal & 5 & 6 & 8 & 19 \\
\hline ", & 6 & 5 & 9 & 7 \\
\hline$"$ & 7 & 64 & 206 & 93 \\
\hline ", & 8 & $<2$ & $<2$ & $<2$ \\
\hline ", & 9 & 13 & 48 & 30 \\
\hline , & 20 & 137 & 162 & 143 \\
\hline ", & 24 & 137 & 374 & 215 \\
\hline , & 26 & 110 & 140 & 128 \\
\hline ", & 28 & 55 & 200 & 122 \\
\hline ", & 31 & 30 & 63 & 33 \\
\hline ", & 33 & 55 & 48 & 56 \\
\hline " & 34 & 167 & 290 & 213 \\
\hline
\end{tabular}

in the cancellous bone, and the difference between compact and cancellous bone aluminium may be considerable when whole bone aluminium is most increased. The difference between compact and cancellous bone aluminium values is statisically significant $(\mathrm{P}<0.02)$.

Bone aluminium and duration of haemodialysis

In general, the highest bone aluminium values occur in the patients dialysed for long periods (Fig. 2). There is a statistically significant correlation between the duration of haemodialysis and the whole bone aluminium only when the non-haemodialysed patients are included (Table 6). When the 17 patients 


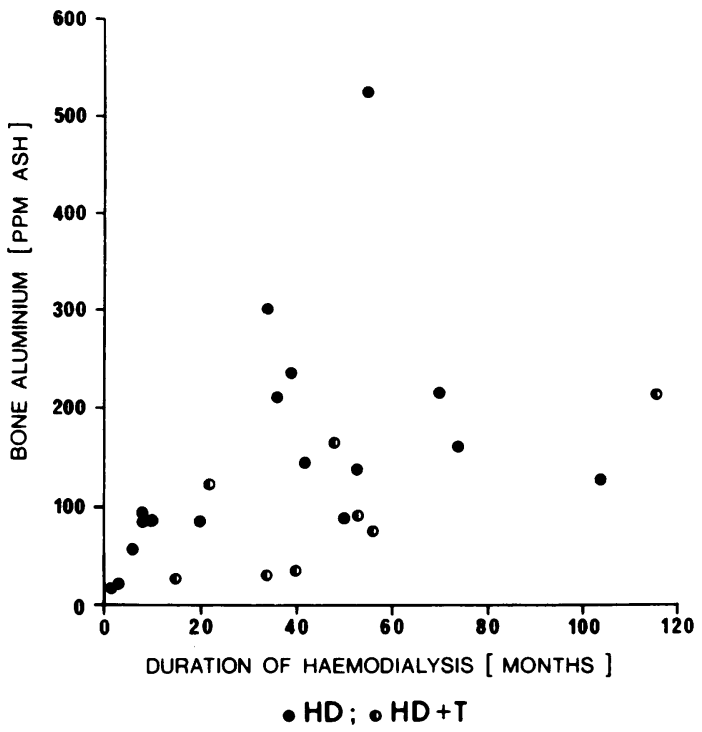

Fig. 2 Relation between whole iliac bone aluminium and duration of haemodialysis: haemodialysis;

(1) haemodialysis and renal transplant.

treated by haemodialysis are considered separately there is no significant relation $(0 \cdot 10>\mathrm{P}>0.05)$.

\section{Relation between bone aluminium and hyperparathyroidism}

The parathyroid glands were enlarged and hyperplastic in the renal patients, irrespective of treatment by haemodialysis or renal transplantation. Although dialysis may be associated with a reduction in the severity of histological osteitis fibrosa the parathyroids remain enlarged. Plotting the weight of parathyroid glands against the bone aluminium concentration reveals no relation in dialysed or nondialysed patients. There is no relation between the histological grade of severity of osteitis fibrosa and the bone aluminium content.

\section{Relation between bone aluminium and osteomalacia} The cause of osteomalacia in non-dialysed patients is almost certainly different from that in many dialysed patients. After renal transplantation there may be a reduction in bone aluminium and/or osteomalacia. Therefore it is justifiable to consider the relation between bone aluminium and osteomalacia only in dialysed patients. Even then there may be several contributing factors. Comparison of the mean bone aluminium concentrations for the dialysed patients divided into two subgroups, depending upon whether or not osteomalacia is present, reveals no statistically significant difference $(0.10>P>0.05)$. This method of grouping may conceal a true relation in individual patients, and it is noteworthy that six with osteomalacia also suffered from dialysis encephalopathy, and five of these had bone aluminium values in excess of $200 \mathrm{ppm}$. None of the dialysed patients without osteomalacia had dialysis encephalopathy (Fig. 3).

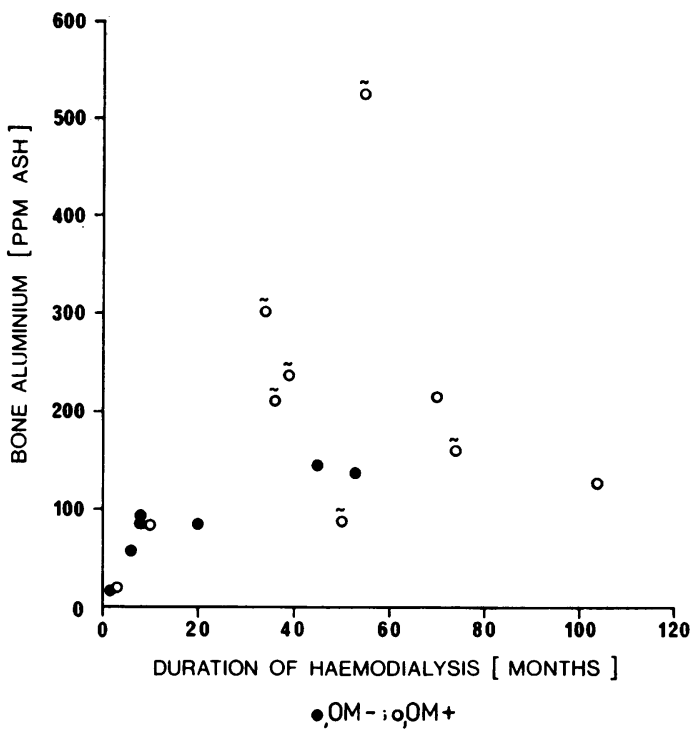

Fig. 3 Relation between whole iliac bone aluminium, duration of haemodialysis, and presence of osteomalacia and dialysis encephalopathy: $\bigcirc$ osteomalacia;

no osteomalacia; $\sim$ dialysis encephalopathy.

Table 6 Iliac whole bone aluminium in relation to duration of haemodialysis

\begin{tabular}{|c|c|c|c|c|}
\hline Group & $\begin{array}{l}\text { Duration } \\
\text { dialysis } \\
\text { (months) }\end{array}$ & $\begin{array}{l}\text { Number } \\
\text { of } \\
\text { patients }\end{array}$ & $\begin{array}{l}\text { Correlation } \\
\text { coefficient }(r)\end{array}$ & Significance \\
\hline
\end{tabular}

HD, haemodialysed; HD/T, haemodialysed and renal transplant 
Regarding the duration and severity of the osteomalacia and the bone aluminium, there is no significant relation between the thickness of the osteoid seams (as indicated by the maximum number of birefringent lamellae) and the bone aluminium (correlation coefficient $r=0 \cdot 218, P>0 \cdot 10$ ).

\section{EXPERIMENTAL RAT DATA}

Experiment 1: 52 days' aluminium chloride injections The test animals failed to gain weight at the normal rate after two to three weeks' injections of aluminium chloride (Fig. 4) but did not develop periorbital bleeding or conjunctival ulceration. There was a fibrinous chemical peritonitis with adhesions, including aluminium granulomata covering the bowel, spleen, and liver. Otherwise there was no histological abnormality of the liver, spleen, pancreas, kidney, heart, or lungs. The serum calcium, phosphorus, alkaline phosphatase, and urea were normal (Table 7). The alkaline phosphatase was of the intestinal type, which is normal in rats. The amount of aluminium in the whole femora of four rats treated with aluminium chloride was increased (range 90-124, mean $109 \cdot 3 \mathrm{ppm}$ of bone ash-Table 7) compared with that in six untreated rats (range 2-30, mean \pm SE, $15.4 \pm 4.7 \mathrm{ppm}$ ) (Tables 7 and 8 ). Radiographs of the tibiae and femora revealed no widening or irregularity of the epiphyseal cartilaginous plates nor change in the width of the zone of metaphyseal spicules of bone and cartilage. Measurements made from radiographs of the tibiae showed that the diaphyseal lengths and the mid-diaphyseal cortical bone widths were unaffected by aluminium chloride treatment (controls: mean $38.0 \mathrm{~mm}$ and $0.9 \mathrm{~mm}$, respectively, compared with $39.1 \mathrm{~mm}$ and $0.9 \mathrm{~mm}$ for test rats).

Undecalcified sections of tibiae confirmed that endochondral ossification was normal with the usual maturation of chondrocytes and mineralisation of cartilage matrix. Where new bone was being formed on the metaphyseal cartilaginous septa, on the inner aspect of the diaphyseal cortical bone, and in the

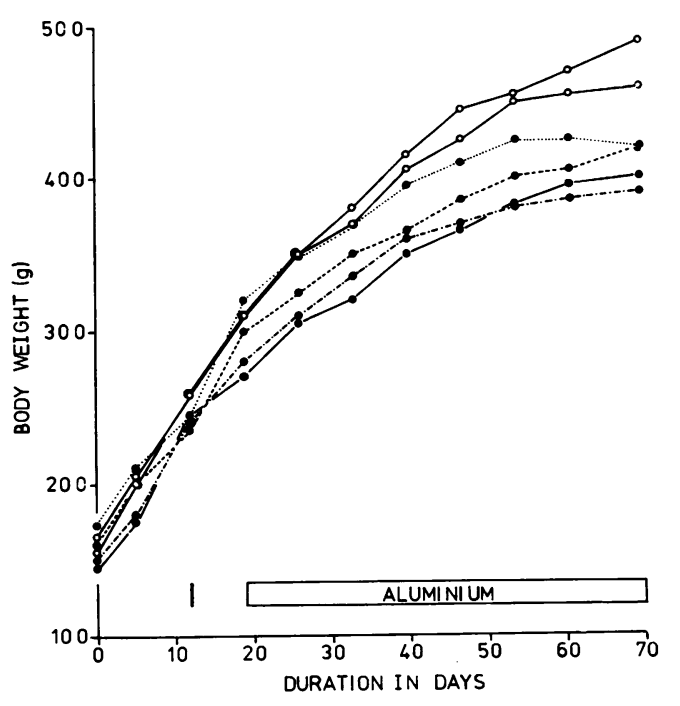

Fig. 4 Growth curves for two control rats $(O)$ and four rats injected with aluminium chloride $(0)$ (experiment 1$)$.

trabeculae of the epiphysis and diaphysis, there was no excess of osteoid, the seams were normal in width, comprising one to two bright lamellae under crossed polaroids, and there was a normal calcification front. Thus, in spite of a marked increase in the bone aluminium, none of the test rats had any histological evidence of a mineralisation defect after 52 days' treatment with aluminium chloride.

\section{Experiment 2}

The test animals failed to gain weight normally, but in those animals in which aluminium chloride injections had been discontinued (rats 17 and 18 for 27 days; rats 13,14 , and 15 for 49 days) there was a subsequent increase in body weight. Four rats $(7,8$, 9, 16) died during the experiment. None of the animals developed periorbital haemorrhages or conjunctival ulceration. General postmortem and

Table 7 Rat experiment 1: Serum chemistry and bone aluminium in four rats injected with $\mathrm{AlCl}_{3}$ and in two controls

\begin{tabular}{|c|c|c|c|c|c|c|c|}
\hline \multirow[t]{2}{*}{ Rat } & \multirow{2}{*}{$\begin{array}{l}\text { Injection } \\
\text { period } \\
\text { (days) }\end{array}$} & \multirow{2}{*}{$\begin{array}{l}\text { Total dose of } \\
\text { aluminium } \\
(m g)\end{array}$} & \multicolumn{4}{|c|}{ Serum chemistry } & \multirow{2}{*}{$\begin{array}{l}\text { Bone } \\
\text { aluminium } \\
\text { (ppm ash) }\end{array}$} \\
\hline & & & $\begin{array}{l}\text { Calcium } \\
(\mathrm{mmol} / \mathrm{l})\end{array}$ & $\begin{array}{l}\text { Phosphorus } \\
\text { (mmol/l) }\end{array}$ & $\begin{array}{l}\text { Alkaline } \\
\text { phosphatase } \\
(U / I)\end{array}$ & $\begin{array}{l}\text { Urea } \\
\text { (mmol/l) }\end{array}$ & \\
\hline $\begin{array}{l}1 \\
2 \\
3 \\
4 \\
5 \\
6\end{array}$ & $\begin{array}{l}52 \\
52 \\
52 \\
52 \\
\text { Saline } \\
\text { Saline }\end{array}$ & $\begin{array}{l}33 \\
35 \\
33 \\
38 \\
1\end{array}$ & $\begin{array}{l}2 \cdot 35 \\
2 \cdot 43 \\
2 \cdot 53 \\
2 \cdot 73 \\
2 \cdot 43 \\
2 \cdot 68\end{array}$ & $\begin{array}{l}2 \cdot 30 \\
2 \cdot 30 \\
2 \cdot 00 \\
2 \cdot 70 \\
2 \cdot 05 \\
2 \cdot 30\end{array}$ & $\begin{array}{l}43 \\
53 \\
63 \\
71 \\
71 \\
66\end{array}$ & $\begin{array}{r}9 \cdot 2 \\
12 \cdot 4 \\
9 \cdot 1 \\
9 \cdot 6 \\
9 \cdot 9 \\
9 \cdot 5\end{array}$ & $\begin{array}{r}114 \\
90 \\
111 \\
124 \\
7 \\
10\end{array}$ \\
\hline
\end{tabular}


Table 8 Rat experiment 2: Serum chemistry and bone aluminium in 16 rats injected with $\mathrm{AlCl}_{3}$ and in four controls

\begin{tabular}{|c|c|c|c|c|c|c|c|}
\hline \multirow[t]{2}{*}{ Rat } & \multirow{2}{*}{$\begin{array}{l}\text { Injection } \\
\text { period } \\
\text { (days) }\end{array}$} & \multirow{2}{*}{$\begin{array}{l}\text { Total dose of } \\
\text { aluminium } \\
(\mathrm{mg})\end{array}$} & \multicolumn{3}{|c|}{ Serum chemistry } & \multirow{2}{*}{$\begin{array}{l}\text { Bone aluminium } \\
\text { (ppm ash) } \\
\text { Whole femur (dia }\end{array}$} & \multirow{2}{*}{ ** } \\
\hline & & & $\begin{array}{l}\text { Calcium } \\
(\mathrm{mmol} / \mathrm{l})\end{array}$ & $\begin{array}{l}\text { Phosphorus } \\
\text { (mmol/l) }\end{array}$ & $\begin{array}{l}\text { Alkaline } \\
\text { phosphatase }(U / l)\end{array}$ & & \\
\hline 7 & $48 *$ & 38 & - & - & - & 120 & - \\
\hline 8 & $50^{*}$ & 39 & - & - & - & 161 & - \\
\hline 9 & $53^{*}$ & 41 & - & - & - & 148 & - \\
\hline 10 & 63 & 53 & $2 \cdot 85$ & $2 \cdot 85$ & 77 & 208 & - \\
\hline 11 & 63 & 53 & $2 \cdot 70$ & $2 \cdot 60$ & 98 & 182 & - \\
\hline 12 & 63 & 54 & $2 \cdot 78$ & $3 \cdot 10$ & 67 & 201 & - \\
\hline 13 & 63 & 50 & $2 \cdot 20$ & 3.00 & 64 & 184 & $(200)$ \\
\hline+14 & 63 & 52 & 2.68 & $3 \cdot 55$ & 48 & 167 & (153) \\
\hline$t_{15}$ & 63 & 53 & $2 \cdot 75$ & $3 \cdot 50$ & 90 & 167 & (181) \\
\hline+16 & $78^{*}$ & 96 & - & - & - & 162 & (156) \\
\hline 17 & 84 & 96 & $2 \cdot 58$ & $3 \cdot 20$ & 65 & 250 & (212) \\
\hline$\mp 18$ & 84 & 99 & $2 \cdot 68$ & 3.90 & 47 & 198 & (232) \\
\hline$\mp 19$ & 85 & 107 & $2 \cdot 55$ & $2 \cdot 55$ & 62 & 124 & (144) \\
\hline 20 & 85 & 107 & $2 \cdot 65$ & $2 \cdot 55$ & 63 & 203 & (188) \\
\hline 21 & 85 & 109 & $2 \cdot 90$ & $3 \cdot 00$ & 99 & 158 & (161) \\
\hline 22 & 85 & 109 & $2 \cdot 65$ & $2 \cdot 60$ & 59 & 183 & (189) \\
\hline 23 & \multirow{4}{*}{\multicolumn{2}{|c|}{$\begin{array}{l}\text { Saline control } \\
\text { Saline control } \\
\text { Saline control } \\
\text { Saline control }\end{array}$}} & 2.65 & $2 \cdot 70$ & 74 & 16 & - \\
\hline 24 & & & $2 \cdot 70$ & $2 \cdot 55$ & 57 & 30 & - \\
\hline 25 & & & $2 \cdot 90$ & $3 \cdot 15$ & 74 & 2 & - \\
\hline 26 & & & $2 \cdot 75$ & $2 \cdot 95$ & 54 & 28 & - \\
\hline
\end{tabular}

*Died, no serum for analysis. **Values in parentheses are aluminium contents of diaphyseal bone free from marrow. †These three rats were left a further 49 days without injections before sacrifice.

$\ddagger$ These two rats were left a further 27 days without injections before sacrifice.

soft-tissue histological findings were the same as in the experiment 1 animals.

The serum biochemical results are given in Table 8. The aluminium-treated rats did not develop hypophosphataemia, and alkaline phosphatase was of the intestinal type.

The whole femur bone aluminium content was increased in the 16 rats given aluminium chloride (mean $\pm \mathrm{SE}=176 \pm 8 \cdot 2 \mathrm{ppm}$ ash compared with $15.4 \pm 4 \cdot 7 \mathrm{ppm}$ for six untreated rats). In 10 test animals where the marrow free diaphysis was also analysed there was a similar increase in aluminium $(181.6 \pm 9.0 \mathrm{ppm})$, confirming that the excess aluminium had accumulated in the bone tissue (Table 8). Bone aluminium remained elevated in the five rats in which aluminium injections were discontinued up to 49 days. Radiographs of the tibiae and femora of the aluminium-injected rats showed no definite widening or irregularity of the epiphyseal cartilaginous plates. In rats 13,14 , and 15 , which had received aluminium over a period of 63 days and then rested for $\mathbf{4 9}$ days, there was a radiodense band at the metaphysis equivalent to about twice the width of the normal radiolucent epiphyseal plate and $1.5 \mathrm{~mm}$ away from it. In rats $19,20,21$, and 22 , after 85 days' aluminium the distinction between the radiolucent epiphyseal plate and the subjacent primary trabeculae zone was less well defined than normal. Rats 17 and 18, after 84 days' aluminium followed by a 27 -day rest period, showed a normal radiolucent epiphyseal plate with a clearcut distinction between the zone of primary trabeculae, but this zone was hazy in appearance. Measurements of the tibial radiographs revealed no definite shortening of the bone. Thus, excluding the four rats which died, the mean length \pm SE for 12 treated rats was $40.0 \pm 0.3 \mathrm{~mm}$ compared with $39.7 \pm 0.7 \mathrm{~mm}$ for the four controls. The treated animals did show some thinning of the cortical bone, only one animal having as thick a cortex as the controls. The mean cortical width at the mid-diaphysis for 12 treated rats was $0.80 \pm 0.03 \mathrm{~mm}$ compared with $1.0 \pm$ $0.4 \mathrm{~mm}$ for the controls.

Undecalcified sections of tibiae revealed an abnormality of bone mineralisation which varied in degree and distribution, depending upon the duration of aluminium treatment, and the various appearances will be described separately:

(a) 4 Control rats: None of the control rats had any evidence of a mineralisation defect of cartilage or bone. At the sites of bone formation the normal osteoid seams comprised one to two lamellae.

(b) Rats dying after 48 to 53 days' aluminium chloride injections (Nos 7, 8, and 9): The epiphyseal cartilaginous plates appeared normal in width and shape, and there was no abnormality of cartilage mineralisation. In rat 7 , after 48 days' aluminium chloride there was no excess of osteoid, the seams comprised 
one to two lamellae, and the calcification front was not reduced. Rats 8 and 9 , after 50 and 53 days' aluminium chloride, respectively, showed a slight excess of osteoid at the metaphysis, lining the internal aspect of the adjacent diaphyseal cortex, and focally on cancellous trabeculae of the epiphysis and diaphysis. In rat 8 the seams were normal in width with one to two lamellae, but in rat 9 some seams comprised four lamellae and lacked a calcification front, and the appearances suggested the onset of a mineralisation defect.

(c) Rats after 63 days' aluminium chloride injections (Nos 10, 11, and 12): Mineralisation of the epiphyseal cartilaginous plate was normal. Although the plate was minimally widened, its outline on the metaphyseal side was regular. New bone forming on the cartilaginous septa appeared as excess osteoid covering the septa for a distance equal to about one-half the depth of the cartilage plate. Rat 11 had wide osteoid seams with up to four lamellae, but the calcification front was not definitely reduced. Rats 10 and 12 had an excess of patchily distributed osteoid on the epiphyseal and diaphyseal trabeculae with wide seams comprising up to five lamellae and with a reduced calcification front, indicating there was osteomalacia.

(d) Rats after 63 days' aluminium chloride, then rested 49 days (Nos 13, 14, and 15): The epiphyseal cartilage plate was normal in width and mineralised. The amount and thickness of new osteoid formed most recently on the cartilage septa by endochondral ossification was normal, in contrast to the excess of osteoid in this site in the rats killed immediatcly after 63 days' aluminium chloride injections. There was a localised zone of thickening of these mineralised trabeculae situated about three cartilage plate depths from the plate and extending for five such depths. This corresponded to the zone of radiodensity noticed on the radiographs (so-calıed 'growth arrest' line). In the diaphysis further away from the cartilage plate the cancellous trabeculae showed a marked excess of lamellar osteoid at the surface, with wide seamscomprising nine lamellae in rat 15 and up to 16 lamellae in rats 13 and 14 . This zone of particularly prominent excess osteoid extended over a distance equal to about 11 epiphyseal plate depths and began at the same distance from the plate. These abnormal osteoid seams, together with those in the epiphysis, frequently lacked a calcification front, although in some there was patchy mineralisation extending over four to five lamellae. These animals thus showed a paradoxical situation of persistence and worsening of features of osteomalacia in parts of the diaphysis and epiphysis after cessation of aluminium chloride treatment and at a time when endochondral ossification, including mineralisation of cartilage and bone, appeared normal.

(e) Rats after 78 to 85 days' aluminium chloride injections (Nos 16 (died 78 days), 19, 20, 21, and 22 (killed 85 days): There was minimal, if any, increase in width of the epiphyseal cartilaginous plates, which were regular in outline. The cartilage septa were mineralised but were covered by an excess of thick woven osteoid including some osteocytes over a length slightly greater than the depth of the epiphyseal plate (Fig. 5). There was patchily distributed excess lamellar osteoid on diaphyseal and epiphyseal trabeculae with wide seams comprising five or six lamellae and with a reduction in the calcification front. Most osteoid was present in rat 20 but all five rats had osteomalacia.

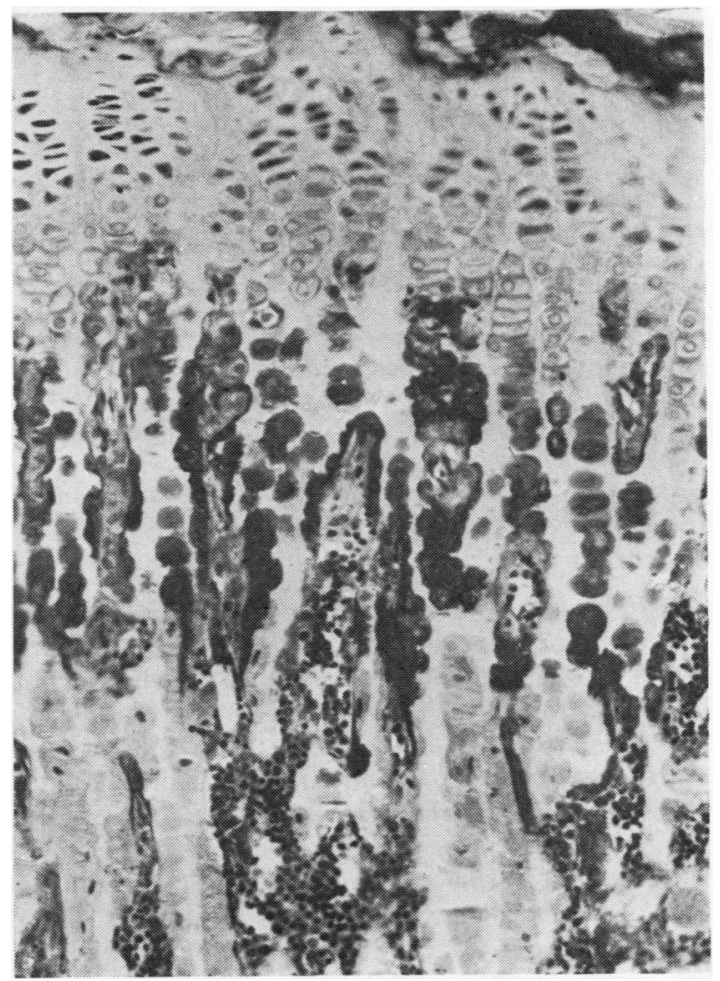

Fig. 5 Proximal end of tibia of rat 22 after intraperitoneal injection of $109 \mathrm{mg}$ Al over 85 days. Note unmineralised new bone formed recently on normal cartilage septa. Goldner's stain, osteoid orange red (appears dark), mineralised bone green (appears grey), mineralised cartilage light green (appears pale). Undecalcified section $\times 150$. 


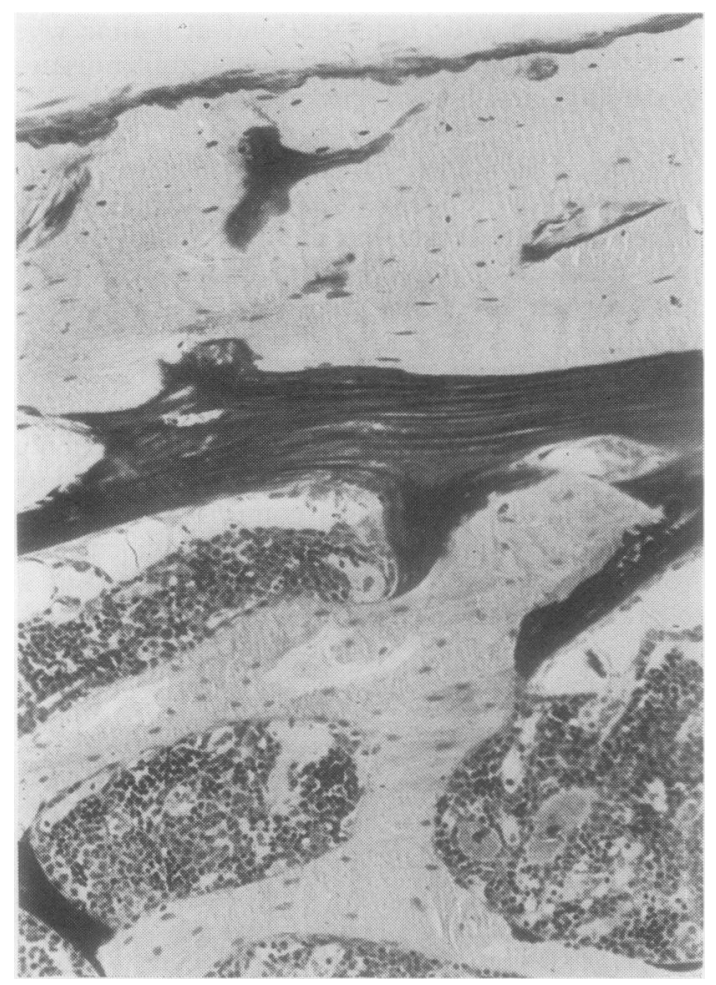

Fig. 6 Diaphysis of tibia of rat 18 after intraperitoneal injection of $99 \mathrm{mg}$ Al over 84 days followed by 27 days rest. Note marked excess of lamellar osteoid with thick seams on the internal aspect of cortical bone and on cancellous trabeculae. Osteoid appears dark. Similar thick osteoid seams were present on the epiphyseal trabeculae, but most recently formed bone on the cartilage septa was mineralised. Undecalcified section Goldner's stain $\times 150$.

(f) Rats after 84 days' aluminium chloride, then rested 27 days (Nos 17 and 18): The epiphyseal cartilaginous plates were normal in width and outline. Mineralisation of the adjacent cartilage septa and bone formed at their surfaces was normal. Starting at a distance equal to one-and-one-half times the depth of the epiphyseal plate, there was a zone of abnormal mineralisation extending for a length of up to one-and-one-half times the depth of the epiphyseal plate. Here the trabeculae comprised a central linear zone of mineralised cartilage with the usual sharply undulating outline of cartilage septa and covered by an excess of osteoid. There was also an excess of patchily distributed osteoid in the epiphyseal trabeculae and on the subperiosteal and endosteal aspects of the compact cortical bone of the diaphysis (Fig. 6). At the metaphysis the endosteal osteoid seam most recently formed was normal in width and possessed a calcification front, but elsewhere in the wide seams the front was reduced. The wide osteoid seams comprised up to seven to 10 lamellae in rats 17 and 18, respectively. Both these animals thus showed features of persistent and worsening osteomalacia away from the zone of endochondral ossification at a time when endochondral ossification itself was normal.

Some of the main changes described in the affected rats are illustrated in Figs. 5 and 6 and are summarised diagrammatically in Fig. 7.

\section{Relation between bone aluminium and amount of aluminium injected}

Bone aluminium was related to the duration of the aluminium injection period and to the total dose of aluminium (Tables 7 and 8 ). There was retention of aluminium in bone for up to 49 days after the cessation of aluminium chloride injections.

\section{Observation on bone linear growth rates in aluminium- treated rats}

Measurements made of the length of abnormal osteoid on the cartilage septa and its distance from the epiphyseal plate in animals rested after aluminium treatment make it possible to estimate the approximate rate of linear growth of bone. Assuming the mineralisation defect was manifest at about 53 days, then to accumulate the measured mean length of $0.07 \mathrm{~mm}$ of osteoid alongside the septa at 63 days the rate was $0.007 \mathrm{~mm} /$ day. At 85 days the mean length of osteoid was $0.27 \mathrm{~mm}$, a gain of $0.2 \mathrm{~mm}$ in 22 days, or a rate of $0.009 \mathrm{~mm}$ per day. During the rest period, after 84 days' injection rats 2 and 5 had a mean length of $0.38 \mathrm{~mm}$ of osteoid $0.29 \mathrm{~mm}$ from the cartilage plate so that the band of osteoid on the cartilage septa had moved $8.67 \mathrm{~mm}$ in 27 days, that is, $0.025 \mathrm{~mm}$ per day. This last rate for rats after the cessation of aluminium is similar to the rate we found previously in normal rats (Ellis and Peart, 1971b) using a tetracycline labelling technique, and the linear rate of growth therefore appears to have been diminished during the course of the aluminium injections.

\section{Discussion}

We have confirmed that the aluminium content of bone is increased in patients with renal disease treated by haemodialysis and found that this aluminium may remain in bone for many months or even years after successful renal transplantation. Patients with chronic renal failure not treated by haemodialysis have less aluminium in their bone, with occasional exceptions such as the patient who had taken large amounts of aluminium hydroxide. 


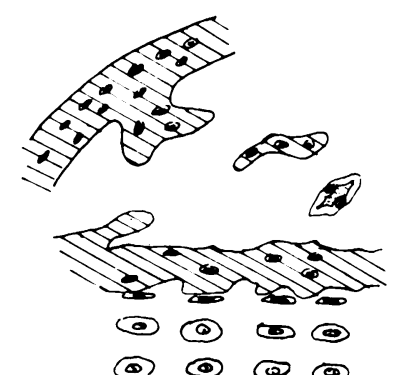

(ब) (ब) (ब)

(ब) (ब) 10

का एक

(अ) 10

(ब) (20)
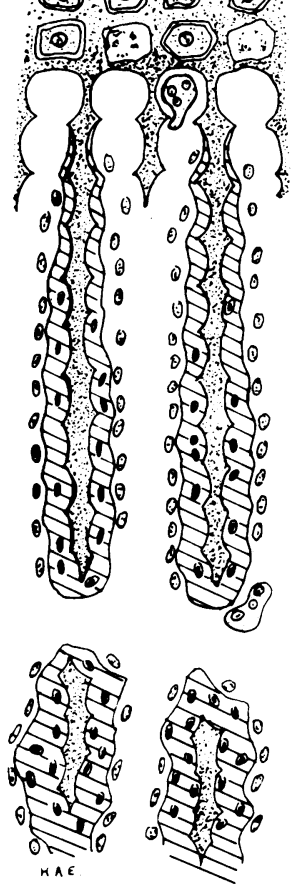
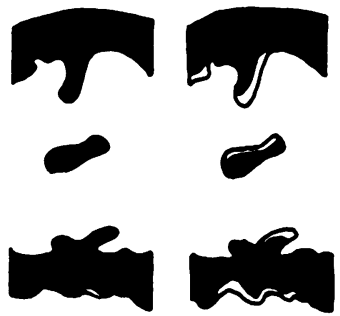

$A L$ NORMAL 85 dys.
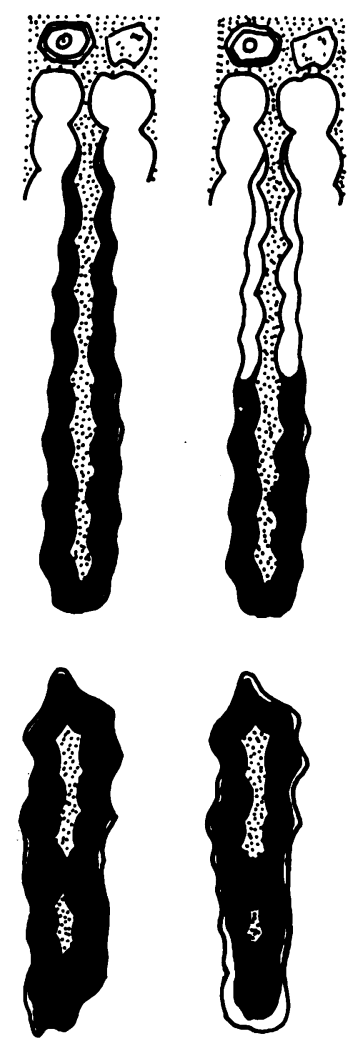
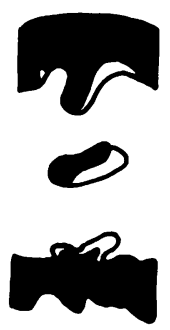

AL

84 dys.

$R$

27 dys.
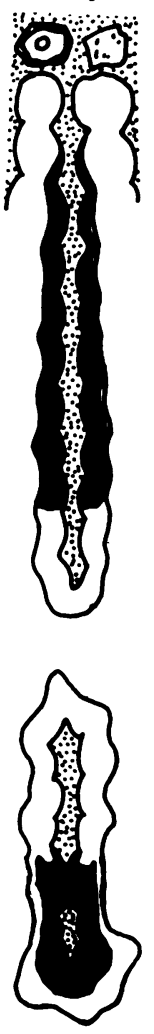

Fig. 7 Diagram to summarise progression of the bone mineralisation defect in rats injected with aluminium chloride. (Left) $A$ representation of normal endochondral ossification at the growing end of a limb bone. (Right) Three simplified drawings with mineralised bone and cartilage represented by black and stippled areas, respectively; osteoid is unshaded. After 85 days' aluminium chloride injections newly-formed bone on the cartilage septa and on the epiphyseal trabeculae has failed to mineralise, although cartilage is normal. After stopping for 27 days, the bone formed on the cartilage septa is mineralising but osteoid previously formed persists and moves towards the diaphysis with linear growth of the septa. The epiphyseal osteoid has also persisted, and the seams are thicker.
This patient also had severe osteomalacia relative to the degree of osteitis fibrosa and terminal symptoms reminiscent of those of dialysis encephalopathy. Although hyperaluminaemia and increased bone aluminium may result from the use of oral aluminium hydroxide and absorption of aluminium may be increased by hyperparathyroidism (Mayor et al., 1977), most of the aluminium in the bones of our dialysis patients was derived from the water used in the dialysate.

The findings that bone aluminium is increased in dialysed patients and that osteomalacia is commoner with increasing time on dialysis do not prove a causal connection between dialysis osteomalacia and increased bone aluminium. There is no statistically significant relation between the presence or severity 
of osteomalacia and the bone aluminium content in our dialysis patients. The situation is complex, however, since, as we noted in the rat experiments, aluminium may accumulate in bone but there is a delay before osteomalacia develops. Furthermore, some of the patients after short periods of haemodialysis may have had $1,25(\mathrm{OH})_{2} \mathrm{D}_{3}$ deficiency osteomalacia such as occurs in non-dialysed patients.

There is a difference between the amounts of aluminium in cortical and cancellous bone in our patients and in those of Alfrey et al. (1976). The difference did not give rise to serious problems in the present study because we used large samples of iliac bone obtained at necropsy, but in vivo studies using transiliac trephine biopsy specimens with widely varying proportions of compact and cancellous bone would be unsatisfactory unless cancellous bone was analysed separately. The increased amount of aluminium in cancellous bone relative to cortical bone is not due to selective accumulation of aluminium in the marrow. Thus when we have separated the marrow from cancellous bone we have found that there is a small amount of aluminium in the marrow, and the major contribution is in the cancellous bone trabeculae.

The rats injected with aluminium chloride failed to gain weight normally, but the weight improved later in those animals in which the injections had been discontinued. We did not observe an aluminium toxicity syndrome such as that described by Berlyne et al. (1972). The four fatalities were the result of penetration of the bowel by a needle at the time of intraperitoneal injection. There was a marked increase in the bone aluminium of the treated rats, and the level achieved was similar to that found in the bones of patients treated by haemodialysis. Analysis of the marrow free femoral diaphysis in some of the rats revealed a concentration of aluminium similar to that found in the opposite whole femur, verifying that the aluminium had accumulated in the bone. The positive relationships between the concentration of bone aluminium and the total amount of aluminium injected or the duration of treatment are to be expected but we were surprised to find that much of the aluminium remained in the bone in those animals rested up to 49 days after courses of aluminium injections, especially as their kidneys were intact. Rats developed a mineralisation defect of bone after 53 days of aluminium treatment, and this increased in severity when the injections were continued. The histological appearance was not that of typical rickets. Thus the cartilage appeared to be normally mineralised, but an excess of osteoid was found on the surface of the cartilaginous primary septa at the usual site of endochondral ossification. The length of this excess osteoid alongside the septa increased with the duration of aluminium treatment. The bones were still growing in length as a result of maturation of cartilage although our measurements showed that the linear growth rate was reduced. The excess osteoid formed on the cancellous trabeculae of the epiphyses and diaphyses was notably patchy in distribution but typical of osteomalacia with abnormally wide seams and no calcification front. There was no associated hypophosphataemia to explain the development of this osteomalacia, and it seems likely that the aluminium chloride was directly responsible.

We have considered the possibility that the aluminium-injected animals, which did not gain weight normally, may have suffered from a deficiency of vitamin $D$ as a result of the reduced dietary intake. However, the rat cube diet was supplemented with vitamin $D_{3}, 1.6 \mathrm{IU} / \mathrm{g}$. Normal rats consume about $25 \mathrm{~g}$ of this daily, equivalent to $40 \mathrm{IU}$ vitamin $D_{3}$, and the aluminium-treated rats consumed at least half this amount, which should have been adequate to prevent osteomalacia. Against there being a simple vitamin $\mathbf{D}$ deficiency osteomalacia is the occurrence of apparently normal cartilage mineralisation when newly formed bone failed to mineralise. The events after cessation of aluminium treatment were also unusual if this had been ordinary vitamin $\mathbf{D}$ deficiency, since with further increase in length of the bone the zone of osteoid persisted but moved down the diaphysis while later bone formed nearer the cartilage plate was normally mineralised. The earlier formed, patchily distributed osteoid on the trabeculae of the epiphysis and diaphysis also persisted and the seams became wider. If there had been a vitamin $\mathbf{D}$ deficiency we would have expected mineralisation of both the old osteoid and the newly formed bone once the deficiency had been rectified. We do not know the precise reasons for this paradoxical mineralısation but it may be correlated with the persistence of excess aluminium in bone formed during aluminium treatment even after aluminium chloride injections have been stopped.

It would be of interest to know the precise localisation of the aluminium in the bone to see if this is in accord with the hypothesis that the accumulated aluminium in the osteoid formed at the time of the aluminium injections prevents proper mineralisation of that osteoid. Unfortunately, we do not have any information concerning the exact site of the bone aluminium, since attempts to locate aluminium in undecalcified bone blocks from patients and rats by Stereoscan scanning electron microscopy or by histochemical means in sections have proved unsuccessful, presumably because of the low concentrations of aluminium involved. Since haemodialysis patients appear to continue accumu- 
lating aluminium in bone with increasing time on dialysis, and osteomalacia also becomes commoner and more osteoid is formed the longer the period of dialysis, it seems likely that some of the aluminium accumulates in the osteoid. There is no information available to indicate how the accumulated aluminium may inhibit normal mineralisation. It has been suggested that treatment with aluminium compounds interferes with phosphate metabolism. Most of the work reported has been based on animals given aluminium hydroxide or chloride by mouth, when the aluminium forms insoluble phosphates in the gastrointestinal tract, causing a negative balance in phosphorus. In such circumstances hypophosphataemia may cause rickets which can be prevented by supplementing the diet with phosphates (Thurston et al., 1972). However, others (Ondreička et al., 1966) have reported that when the effects on the absorption of phosphorus are eliminated, then feeding high doses of aluminium salts still affects phosphorylation mechanisms in the tissues. The absence of hypophosphataemia in our animals does not exclude the possibility that aluminium chloride interferes with phosphate metabolism in bone tissues.

The present experiments have revealed a hitherto undescribed and unusual form of mineralisation defect, histological osteomalacia developing in rats after the long-term intraperitoneal administration of aluminium chloride and unaccompanied by hypophosphataemia. The experiments do not conclusively prove that aluminium toxicity is the direct cause of the osteomalacia. We are currently carrying out further experiments with this model to ascertain whether or not the development of osteomalacia in aluminium chloride injected rats can be prevented or treated by supplements of parenteral vitamin $D$. As a further precaution we are also studying the mineralisation status of bone in a pair weight gain control to each of the animals treated with aluminium chloride.

If it is subsequently proved that aluminium is indeed directly interfering with bone mineralisation then the present experimental results would have some important implications for haemodialysis patients. In particular, the retention of aluminium in the bones of rats after the cessation of aluminium treatment, even in the presence of intact kidneys, suggests that once the patients' bones are loaded with aluminium elimination might be difficult and the aluminium could exert a detrimental effect on mineralisation long after exposure to aluminium had ceased. Thus osteomalacia might persist after substitution of a dialysate prepared from a water supply with a lower concentration of aluminium or after renal transplantation.
We are indebted to Dr A. Skillen, of the Department of Clinical Biochemistry, University of Newcastle upon Tyne, and to Mr S. R. Munt, of the Atomic Weapons Research Establishment, for carrying out the serum and neutron activation analyses. We thank $\mathrm{Mr}$ W. H. B. Mawhinney for valuable technical assistance with the histological preparations and Professor D. N. S. Kerr for providing the clinical data. We are also indebted to the DHSS Scientific and Technical Branch for funding the aluminium analyses.

\section{References}

Alfrey, A. C., LeGendre, G. R., and Kaehny, W. D. (1976). The dialysis encephalopathy syndrome. Possible aluminium intoxication. New England Journal of Medicine, 294, 184-188.

Berlyne, G. M., Ben-Ari, J., Pest, D., Weinberger, J., Stern, M., Gilmore, G. R., and Levine, R. (1970). Hyperaluminaemia from aluminium resins in renal failure. Lancet, 2, 494-496.

Berlyne, G. M., Yagil, R., Ben-Ari, J., Weinberger, G., Knopf, E., and Danovitch, G. M. (1972). Aluminium toxicity in rats. Lancet, 1, 564-568.

Elliott, H. L., Dryburgh, F., Fell. G. S., Sabet, S., and MacDougall, A. I. (1978). Aluminium toxicity during regular haemodialysis. British Medical Journal, 1, 1101-1103.

Ellis, H. A., and Peart, K. M. (1971a). Renal osteodystrophy with particular reference to the effects of chronic intermittent haemodialysis (Abstract). Nephron, 8, 402.

Ellis, H. A., and Peart, K. M. (1971b). Dextran sulphate osteopathy in parathyroidectomised rats. British Journal of Experimental Pathology, 52, 684-695.

Ellis, H. A., and Peart, K. M. (1973). Azotaemic renal osteodystrophy: a quantitative study on iliac bone. Journal of Clinical Pathology, 26, 83-101.

Ellis, H. A., Pierides, A. M., Feest, T. G., Ward, M. K., and Kerr, D. N. S. (1977). Histopathology of renal osteodystrophy with particular reference to the effects of $1 \alpha$ Hydroxyvitamin $D_{3}$ in patients treated by long-term haemodialysis. Clinical Endocrinology, 7, Supplement, 31 S-38 S.

Gilmour, J. R. (1947). The Parathyroid Glands and Skeleton in Renal Disease, Cumberlege, Oxford University Press, London.

Goode, G. C., Herrington, J., and Goddard, P. C. (1977). Neutron activation analysis for aluminium in bone and tissue samples. Radiochemical and Radioanalytical Letters, 31 (2), 87-94.

McDermott, J. R., Smith, A. I., Ward, M. K., Parkinson, I. S., and Kerr, D. N. S. (1978). Brain aluminium concentration in dialysis encephalopathy. Lancet, 1, 901-904.

Mayor, G. H., Makdani, D. D., and Keiser, J. A. (1977). The effect of parathyroid hormone (PTH) on the gastrointestinal (GI) absorption and distribution of 
aluminium. In Clinical Chemistry and Chemical Toxicology of Metals, edited by S. S. Brown, pp. 41-44. Elsevier/North Holland Biomedical Press, Amsterdam.

Ondreička, R., Ginter, E., and Kortus, J. (1966). Chronic toxicity of aluminium in rats and mice and its effects n phosphorus metabolism. British Journal of Industrial Medicine, 23, 305-312.

Parsons, V., Davies, C., Goode, C., Ogg, C., and Siddiqui, J. (1971). Aluminium in bone from patients with renal failure. British Medical Journal, 4, 273-275.

Pierides, A. M., Ellis, H. A., Simpson, W., Dewar, J. H., Ward, M. K., and Kerr, D. N. S. (1976). Variable response to long-term $1 \alpha$-Hydroxycholecalciferol in haemodialysis osteodystrophy. Lancet, 1, 1092-1095.

Platts, M. M., Goode, G. C., and Hislop, J. S. (1977).
Composition of the domestic water supply and the incidence of fractures and encephalopathy in patients on home dialysis. British Medical Journal, 2, 657-660.

Thurston, H., Gilmore, G. R., and Swales, J. D. (1972). Aluminium retention and toxicity in chronic renal failure. Lancet, 1, 881-883.

Ward, M. K., Feest, T. G., Ellis, H. A., Parkinson, I. S., Kerr, D. N. S., Herrington, J., and Goode, G. L. (1978). Osteomalacic osteodystrophy: evidence for a water-borne aetiological agent, probably aluminium. Lancet, 1, 841-845.

Requests for reprints to: Dr H. A. Ellis, Department of Histopathology, The Royal Victoria Infirmary, Queen Victoria Road, Newcastle upon Tyne NE1 4LP, UK. 